\title{
Effect of microstructure refinement on low cycle fatigue behavior of Alloy 718
}

\author{
Shamil Mukhtarov ${ }^{\mathrm{a}}$ and Farid Utyashev \\ Institute for Metals Superplasticity Problems of the Russian Academy of Sciences, 450001 Ufa Stepana Khalturina 39, \\ Russia
}

\begin{abstract}
Microstructure refinement down to $\mathrm{d} \sim 0.1-1 \mu \mathrm{m}$ is known to enhance processing properties of hardto-deform materials and particularly can be used for facilitating superplastic forming or roll-forming. However refined microstructure can compromise service properties, particularly fatigue properties. In the present work, the fatigue behavior of the fine-grained Alloy 718 has been investigated. A number of fine-grained conditions with a grain size $\sim 0.1-1 \mu \mathrm{m}$ were produced using multiple forging with a graduate decrease of the forging temperature. Part of the forged fine-grained conditions was also subjected to conventional solution annealing and ageing. In this case a small grain size was controlled by precipitates of the $\delta$ phase located on grain boundaries. Low cycle fatigue tests of the fine-grained conditions were carried out at room and elevated temperatures. The obtained properties are compared with those of the Alloy 718 in the coarse-grained conditions. The effect of the grain size on the fatigue strength of the fine-grained Alloy 718 is discussed in terms of the microstructure evolution and fracture mode.
\end{abstract}

\section{Introduction}

Fine-grained Alloy 718 produced by multiple forging and having a grain size as small as $\sim 0.1 \mu \mathrm{m}$ demonstrates superplastic properties at $700{ }^{\circ} \mathrm{C}[1]$. At this temperature and low strain rates, higher values of the strain rate sensitivity coefficient and the elongations were reached. Clearly, superplastic forming is only an intermediate processing step taking into account that final heat treatment should be performed to provide desirable mechanical properties including acceptable high-temperature capability. The final heat treatment normally includes solution annealing and precipitation hardening. In so doing, the Alloy 718 is hardened by precipitation of the secondary phases $\gamma^{\prime \prime}+$ $\gamma^{\prime}$ in the metal matrix [2]. The major strengthening metastable $\gamma^{\prime \prime}$ phase is dissolved at $650^{\circ} \mathrm{C}$ and higher temperatures; the precipitation of the equilibrium $\delta$ phase occurs within the temperature range of $750-1020^{\circ} \mathrm{C}$. It is known that the $\delta$-phase can have a significant influence on the mechanical properties of the alloy. Particularly, it has been reported [3] that the $\delta$-phase precipitates affected the stress-rupture strength and fatigue properties of the fine-grained alloy. In references [4-6] the comparison of mechanical properties of a duplex $(\gamma+\delta)$ Alloy 718 with different grain sizes obtained by multiple forging was carried out at room temperature. The alloy with a grain size of $\mathrm{d}=0.1 \mu \mathrm{m}$ showed much higher ultimate tensile strength than that of the coarse-grained alloy $\left(\sigma_{\mathrm{UTS}}=\right.$ $1920 \mathrm{MPa}$ against $\left.\sigma_{\mathrm{UTS}}>1276 \mathrm{MPa}\right)$. An additional two hour annealing at $600{ }^{\circ} \mathrm{C}$ increased the ultimate tensile

\footnotetext{
${ }^{a}$ Corresponding author: shamil@anrb.ru
}

strength up to $2024 \mathrm{MPa}$. At the same time, some a reduction of ductility in the ultrafine-grained alloy was detected. It should be noted that there is not data concerning the influence of the multiple forging followed by heat treatment on the fatigue behavior of the Alloy 718 . Hence, the aim of the present work was to evaluate the influence of microstructure refinement by multiple forging followed by heat treatment on the fatigue properties and microstructure evolution of the Alloy 718.

\section{Material and experimental methods}

The hot-deformed nickel based Alloy 718 was taken as an initial material. The chemical composition of the alloy is (in wt.\%): $18.3 \mathrm{Cr} ; 18.4 \mathrm{Fe} ; 5.1 \mathrm{Nb} ; 0.56 \mathrm{Al} ; 1.05 \mathrm{Ti} ; 2.9 \mathrm{Mo}$; $0.1 \mathrm{Co} ; 0.05 \mathrm{C} ; 0.025 \mathrm{~B}$; Ni balance. The samples were machined from $250 \mathrm{~mm}$ diameter billet.

Microstructure of the initial material was fully recrystallized, relatively coarse-grained with a mean grain size of about $20 \mu \mathrm{m}$. TEM studies have shown that coherent disk-type $\gamma^{\prime \prime}$-precipitates are uniformly distributed within the $\gamma$ matrix [6]. The $\gamma$ phase grain boundaries were decorated with $\delta$ phase plates. Carbides with a mean size of about $5 \mu \mathrm{m}$ are present in the microstructure.

The fine-grained workpieces were produced using multiple forging. The forging procedure was performed on a hydraulic press equipped by isothermal die unit in the step by step decreasing temperature from $950^{\circ} \mathrm{C}$ down to $575^{\circ} \mathrm{C}$ using flat die tool. Three different forging procedures were used within the present work. Multiple forging at $950{ }^{\circ} \mathrm{C}$ resulted in a fine-grained structure with 


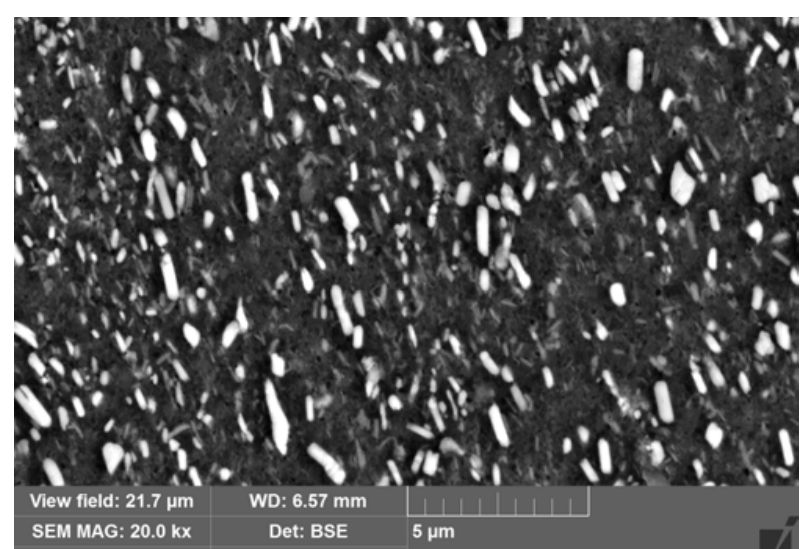

Figure 1. SEM image of Alloy 718 subjected multiple forging with temperature decreasing down to $575^{\circ} \mathrm{C}$.

the grain size about of $10 \mu \mathrm{m}$. A decrease in the forging temperature down to $800{ }^{\circ} \mathrm{C}$ led to formation of the finegrained structure with the grain size about of $1 \mu \mathrm{m}$. A subsequent decrease in the forging temperature down to $575^{\circ} \mathrm{C}$ resulted in a uniform microstructure with a mean grain size of about $0.1 \mu \mathrm{m}$ (Fig. 1). The $\gamma^{\prime \prime}$ phase was dissolved during forging and the deformation induced $\delta$ phase uniformly precipitated as plates. The produced ultrafine-grained condition was very non-equilibrium taking into account non-coherent boundaries between the matrix and $\delta$ phase as well as a high dislocation density [6].

The forged workpieces had dimensions $\emptyset 60-80 \mathrm{~mm} \times$ $20-60 \mathrm{~mm}$. The standard heat treatment of the forged material was carried out in accordance with the AMS 5662 [2]: solution annealing at $980-990^{\circ} \mathrm{C}(1 \mathrm{~h}$.) followed by aging at $720^{\circ} \mathrm{C}\left(8 \mathrm{~h}\right.$.), furnace cooling to $620^{\circ} \mathrm{C}$ and holding at $620^{\circ} \mathrm{C}$ for the total aging time of 18 hours. The Schenck HYDROPULS PSA 10 testing machine was used for the room temperature fatigue tests. The tensiontension fatigue tests were carried out at room temperature using mechanically polished samples with a gauge section of $4 \mathrm{~mm}$ in diameter and $25 \mathrm{~mm}$ in length. The axial fatigue tests were carried out at a frequency of $10 \mathrm{~s}^{-1}$ and a loading of 910 and $696 \mathrm{MPa}$ to compare with the results obtained for the conventionally processed alloy. The tension-compression low cycle fatigue tests were performed at room temperature and $650^{\circ} \mathrm{C}$ with a strain rate of $0.5 \mathrm{~s}^{-1}$ and a total strain ranging from 1 to $2 \%$. Mechanically polished specimens with a gauge section of $5 \mathrm{~mm}$ in diameter and $18 \mathrm{~mm}$ in length were used in this case. A closed loop servo controlled hydraulic testing machine Instron 8001 was used for these fatigue tests. All the tests were conducted using a triangular wave form at $\mathrm{R}=-1$. The microstructure and fracture characterization was performed by means of JEOL JEM2000EX transmission electron microscope (TEM) and Tescan Vega $3 \mathrm{SBH}$ scanning electron microscope (SEM).

\section{Results and discussion}

\subsection{Microstructure and mechanical properties of the alloy after multiple forging and conventional heat treatment}

Two forged workpieces of the Alloy 718 with a grain size about 1 and $0.1 \mu \mathrm{m}$ were subjected to conventional heat

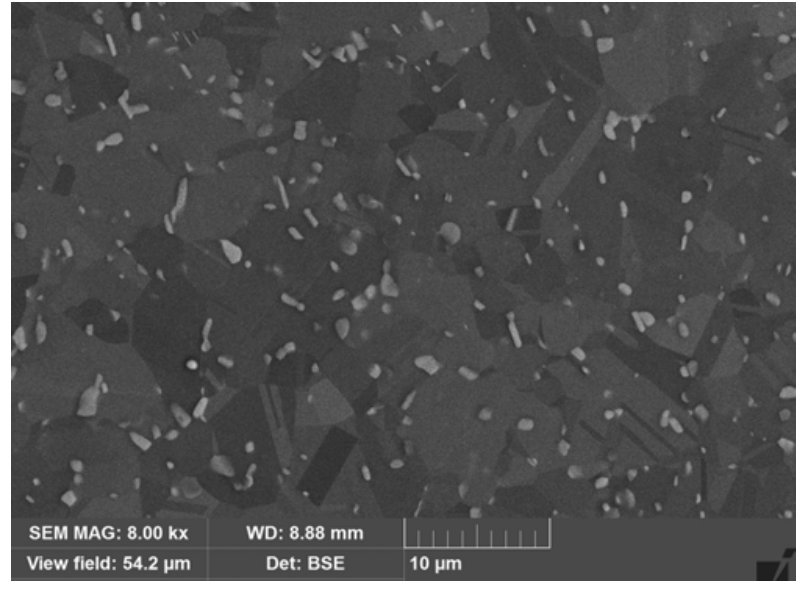

Figure 2. Microstructure of Alloy 718 multiple forged with temperature decreasing down to $800^{\circ} \mathrm{C}$, annealed and aged.

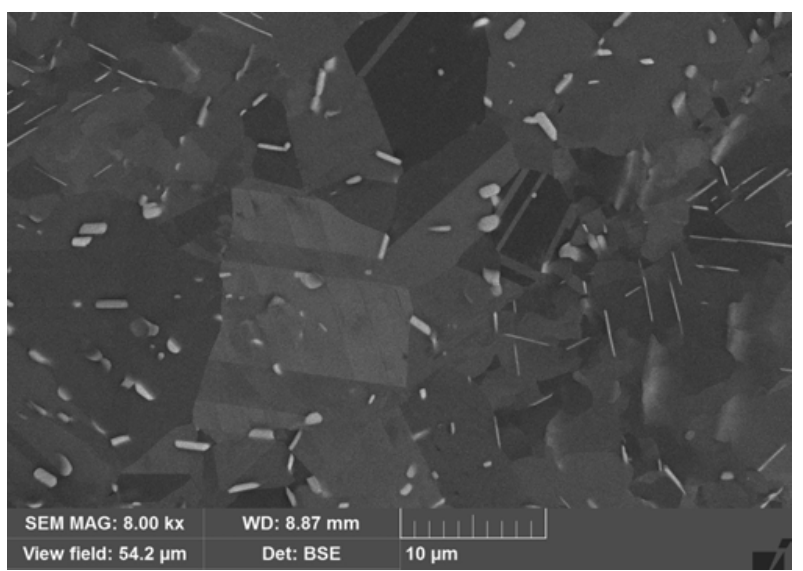

Figure 3. Image of Alloy 718 forged at $950^{\circ} \mathrm{C}$, annealed and aged.

treatment. One can see that a homogeneous microstructure with an average grain size of $\gamma$-phase about $4.5 \mu \mathrm{m}$ was reached in the both cases. Note that not all $\delta$ phase plates were dissolved during the annealing process (Fig. 2). The volume fraction of the $\delta$ phase was about $3 \%$. The third forged workpiece with the grain size about of $10 \mu \mathrm{m}$ retained the same grain size after the heat treatment. In the microstructure, the $\delta$ phase plates were also observed around and within the $\gamma$ grains (Fig. 3).

Paper [6] presents the mechanical properties data on the heat treated alloy. These data obviously meet the material specification requirements [2]. AMS 5662 data shows minimal required properties of the alloy after conventional heat treatment. Tensile properties of the finegrained alloys after heat treatment are compared with properties of heat treated coarse-grained alloy which is presented in work [7]. The data from [7] shows that the refinement of $\gamma$ phase grain size leads to some increase in strength at room temperature but some decrease in strength at $650{ }^{\circ} \mathrm{C}$, the plasticity at these tests are about the same.

Stress rupture data of fine-grained alloy in comparison with the coarse-grain alloy are given in work [7]. All properties meet the material specification requirements. It is significant that fine-grained alloy has increased ductility. 
Table 1. Fatigue strength properties of Alloy 718 after heat treatment.

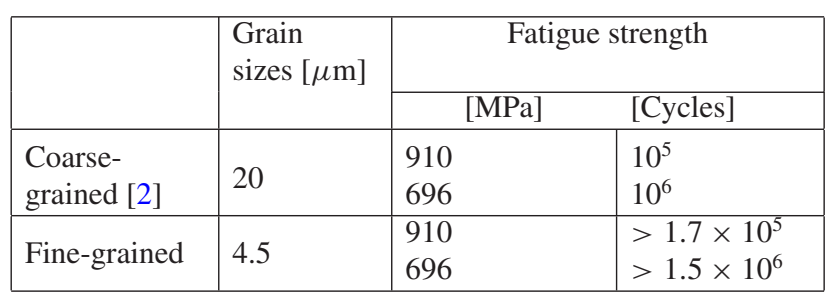

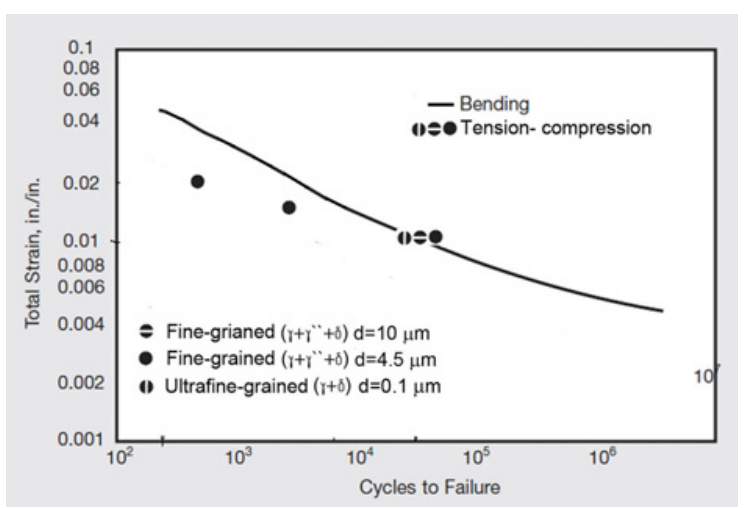

Figure 4. Low cycle life of plate (test orientation parallel to rolling direction, $\mathrm{d}=53 \mu \mathrm{m}$ ) [2] and forgings with fine-grained structures annealed and aged in accordance with AMS 5596 and ultrafine-grained structure without any treatment.

All presented mechanical properties show that the presence of $\delta$ phase leads to increase strength at room temperature due to reduction of $\gamma^{\prime \prime}$ phase and finer $\gamma$ grains of structure. Both smaller grain size and concentration of $\gamma^{\prime \prime}$ phase at this structure raise plasticity at $650{ }^{\circ} \mathrm{C}$ long term testing.

\subsection{Fatigue strength tests at room and elevated temperature}

Room-temperature fatigue properties of annealed and aged fine-grained forging specimens are shown in Table 1 in comparison with data of hot-rolled bar [2] after rotatingbeam tests. Those specimens had structure with an average grain size of about $20 \mu \mathrm{m}$. The fine-grained alloy ( $\mathrm{d}=$ $4.5 \mu \mathrm{m}$ ) fatigue strength on the base of $10^{5}$ cycles at the strain $910 \mathrm{MPa}$ is higher by the factor of 1.7 compared to the coarse-grained alloy data predetermined earlier [2]. The same tests at strain of $696 \mathrm{MPa}$ have shown that the fine-grained alloy properties on the base of $10^{6}$ cycles are also higher. Additional research on the tension-tension fatigue test of coarse-grained alloy is required.

Low cycle fatigue tests of fine-grained alloys at room temperature were carried out to compare with data [2]. The test results are shown in Fig. 4. At total strain of $1 \%$ the low cycle fatigue life of Alloy 718 with different structure is about the same whether tested in bending or in tension-compression. Fine-grained specimens with the grain size of about $4.5 \mu \mathrm{m}$ and $10 \mu \mathrm{m}$, were compared with the coarse-grained $(\mathrm{d}=53 \mu \mathrm{m})$ specimens. The ultrafinegrained $(\mathrm{d}=0.1 \mu \mathrm{m})$ alloy without any treatment have shown also the same result as heat treated specimens.

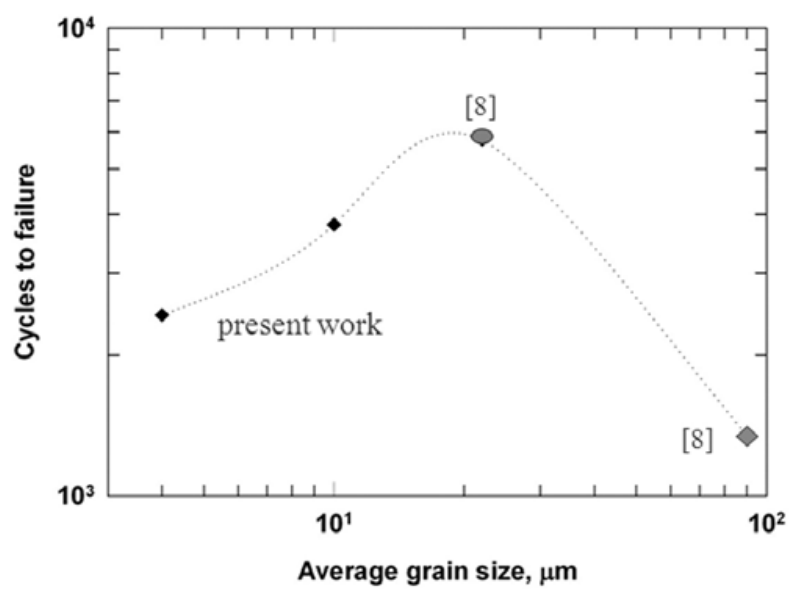

Figure 5. Effect of grain size on number of cycles to failure at $650{ }^{\circ} \mathrm{C}$ and $1 \%$ total strain of Alloy 718 annealed and aged in accordance with AMS 5662.

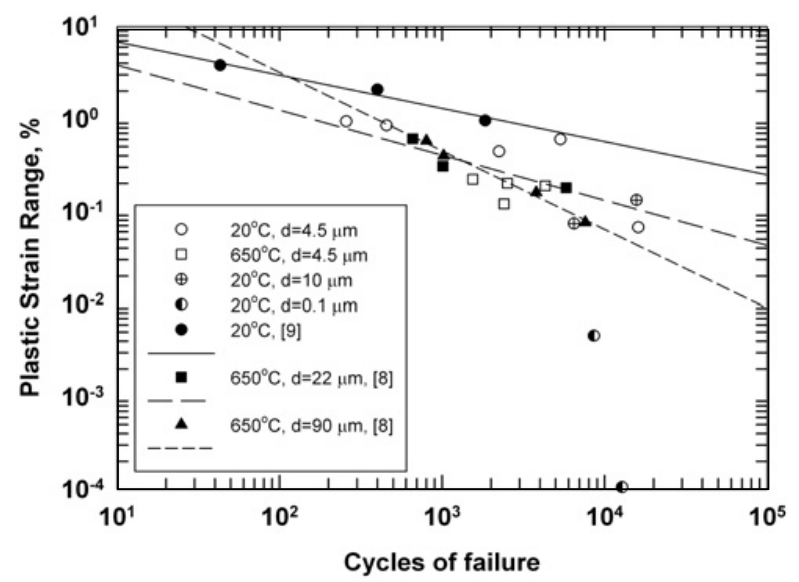

Figure 6. Dependence of fatigue life of Alloy 718 on plastic strain range and different grain size.

Such properties of ultrafine-grained alloy, probably, were closely related with large work for crack nucleation on ultrafine-grained surface of specimens. At total strain of $1.5 \%$ and $2 \%$ the low cycle fatigue life of fine-grained alloy are about of $2 \times 10^{3}$ and $4 \times 10^{2}$ cycles, accordingly. Rigid circuit of the tensile-compression test was compared to bending (Modified Krouse plate fatigue machine), probably, led to early breakage of the specimens.

Low cycle fatigue tests of forged Alloy 718 with finegrained structures were carried out at $650^{\circ} \mathrm{C}$ and $1 \%$ of total strain. Test results show the data within interval that was reported earlier [8]. Figure 5 shows the effect of $\gamma$ grain size on the fatigue life that summarized results of a present work and paper [8]. It is evident that the number of cycles to failure at total strain range $1 \%$ and $650{ }^{\circ} \mathrm{C}$ depends on the grain size. The decreasing of grain size from $90 \mu \mathrm{m}$ down to $22 \mu \mathrm{m}$ the number of cycles to failure increased. Additional reduction of grain size down to $4.5 \mu \mathrm{m}$ leads to decrease the fatigue life. It can really be, because this fine-grained alloy $(\mathrm{d}=1-2 \mu \mathrm{m})$ revealed good superplasticity at $700{ }^{\circ} \mathrm{C}$ [5].

The effect of plastic strain cycling on the fatigue life of Alloy 718 at room temperature and $650{ }^{\circ} \mathrm{C}$ is shown in Fig. 6. The number of cycles to fracture is given in terms 


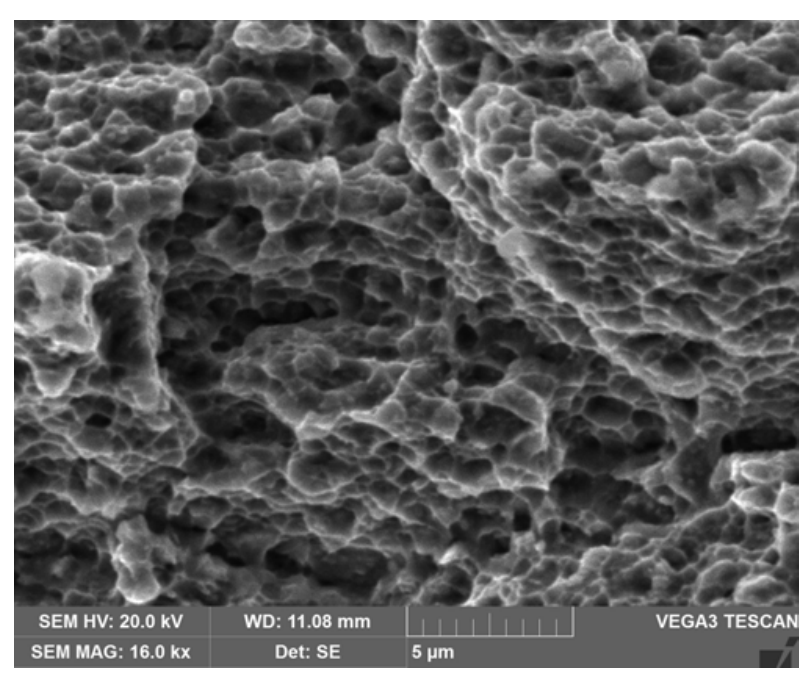

Figure 7. Image of fracture surface of ultrafine-grained Alloy 718 at high magnification.

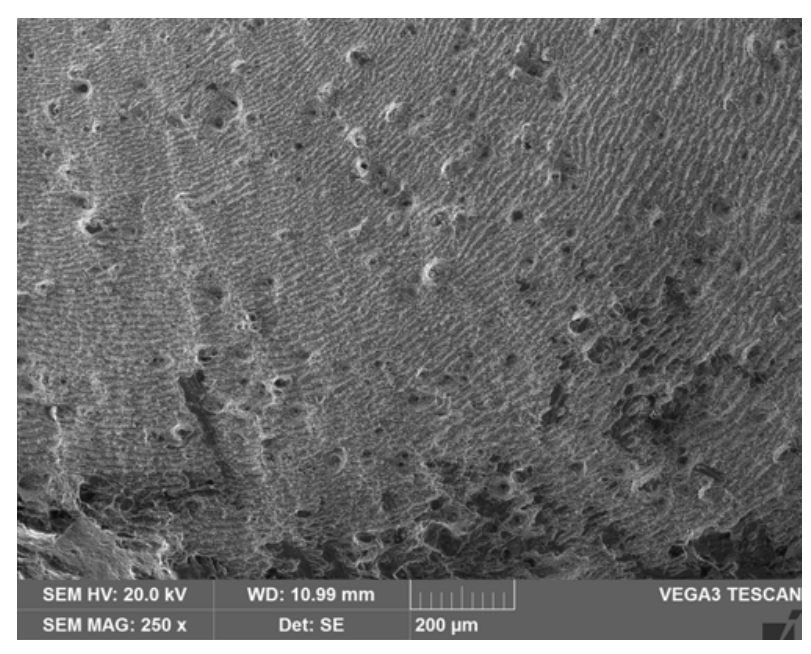

Figure 8. Image of fracture surface of ultrafine-grained Alloy 718 at low magnification.

of the plastic strain range to which the alloy was subjected. The results of papers $[8,9]$ and present work show that the increase in fatigue life occurs when the grain size within interval of 4.5-25 $\mu \mathrm{m}$. Ultrafine-grained alloy without any treatment shows a large number of cycles at low plasticity.

The fracture surface and microstructure investigations of specimens subjected to low cycle fatigue tests were carried out. Fracture surface of the ultrafinegrained specimen at high magnification have demonstrated the typical picture of nanostructured material with submicrometer-scale dimpled features (Fig. 7). At low magnification of the fracture surface in Fig. 8 one can see the shear regions described in the overview [10]. Deformed fracture surface was revealed at the edge area of specimen. This area was formed immediately after the crack nucleation. TEM study of microstructure showed that structure did not change during test at room temperature.

The fracture surface of fine-grained $(\mathrm{d}=4.5 \mu \mathrm{m})$ specimens subjected to fatigue at room and $650^{\circ} \mathrm{C}$ have demonstrated the typical dimpled structure (Fig. 9). The

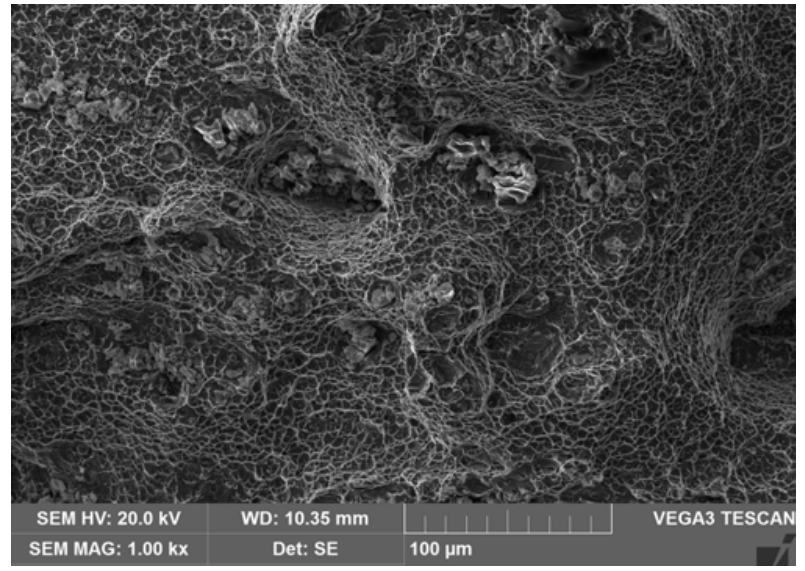

Figure 9. The fracture surface of fine-grained Alloy $718(\mathrm{~d}=$ $4.5 \mu \mathrm{m})$ after low cycle fatigue test at $650^{\circ} \mathrm{C}(2405$ cycles $)$.

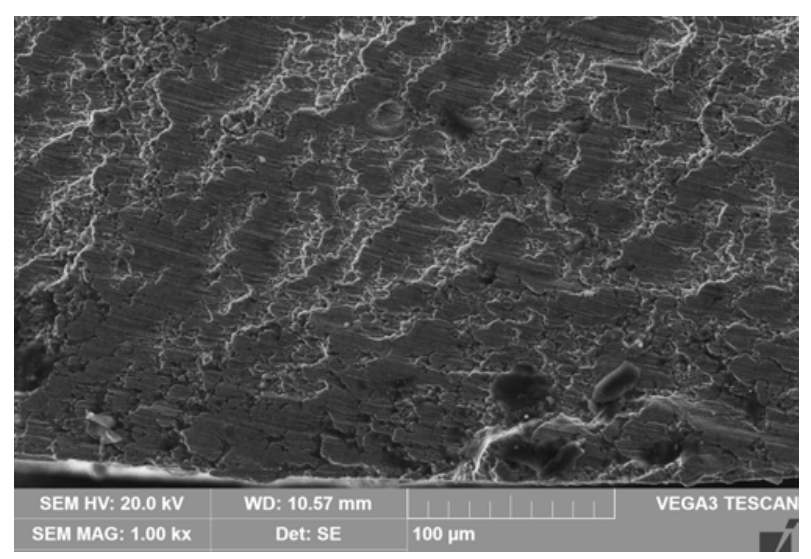

Figure 10. Image of deformed fracture surface of fine-grained Alloy 718 at the edge area of the specimen after low cycle fatigue test at $6500^{\circ} \mathrm{C}$.

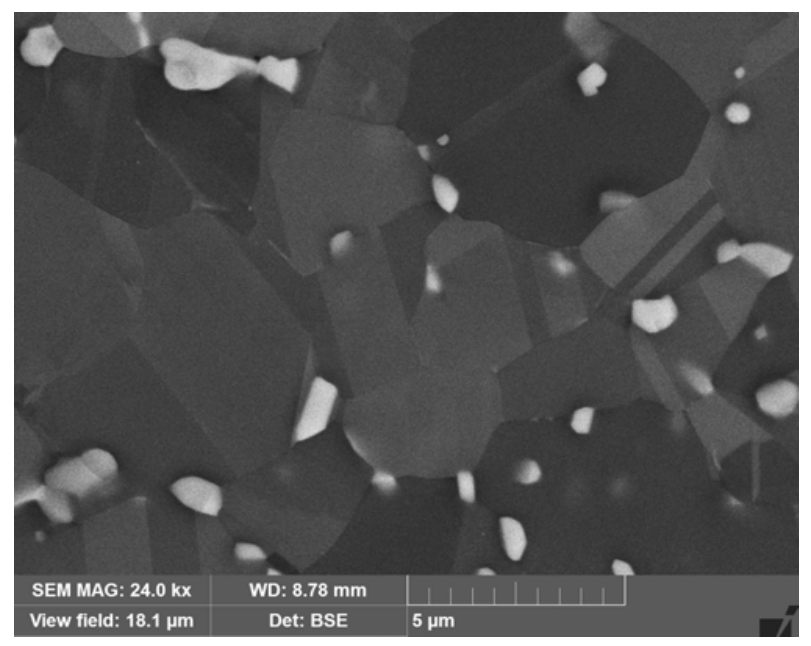

Figure 11. Microstructure of fine-grained Alloy 718 (d = $4.5 \mu \mathrm{m})$ after low cycle fatigue test at $650^{\circ} \mathrm{C}$.

size of dimples was the same as the size of $\gamma$ grains. The fracture mainly occurred along grain boundaries. The deformed fracture surface was also revealed at the edge area of all fine-grained specimens (Fig. 10).

Microstructure investigation after the test at room temperature and $650^{\circ} \mathrm{C}$ (Fig. 11) showed that the structure remained the same. TEM image at Fig. 12 shows that 


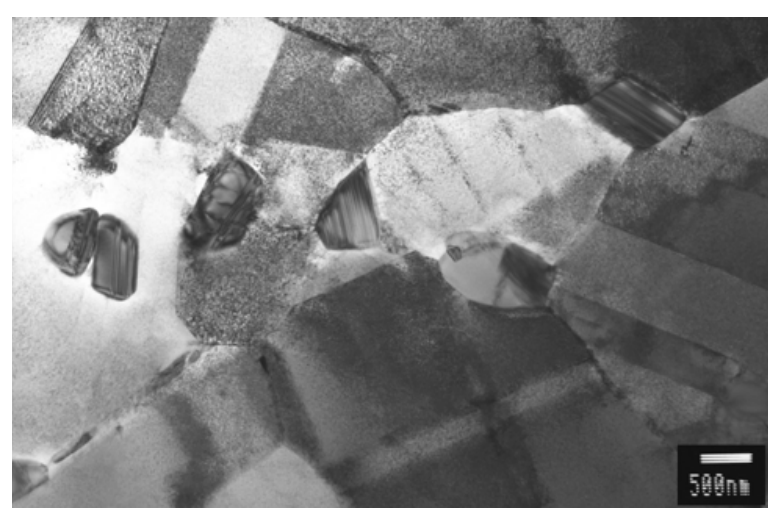

Figure 12. TEM image of fine-grained Alloy $718(\mathrm{~d}=4.5 \mu \mathrm{m})$ after low cycle fatigue test at $650^{\circ} \mathrm{C}$.

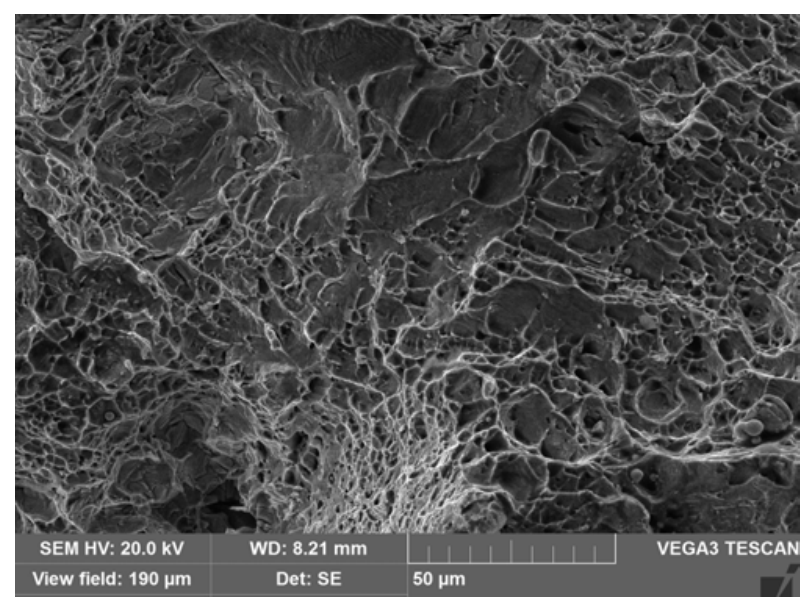

Figure 13. Image of the fracture surface of fine-grained Alloy $718(\mathrm{~d}=10 \mu \mathrm{m})$ after low-cycle fatigue test at room temperature.

annealing twins and dislocations were formed on some $\delta$ plates.

Fine-grained $(d=10 \mu \mathrm{m})$ specimens had more developed fracture (Fig. 13). The surface consists of large and small dimples, and small area of striation pattern that is typical for the transgranular fracture. Striation patterns at fracture surface are probably due to the presence of large individual grains in the fine-grained structure.

As a result of the present study the use of Alloy 718 with an average grain size about of $15-25 \mu \mathrm{m}$ leads to increased low cycle fatigue because fatigue passage along to grain boundary is longer.

\section{Conclusions}

1. The low cycle fatigue life of Alloy 718 at room temperature and a total strain $1 \%$ was approximately the same irrespective of the grain size.

2. Alloy 718 with a grain size around $20 \mu \mathrm{m}$ showed slightly higher low cycle fatigue life at $650{ }^{\circ} \mathrm{C}$ than that of the alloy with a smaller grain size.

\section{References}

[1] V.A. Valitov, Sh.Kh. Mukhtarov, Yu.A. Raskulova, Rev. Adv. Mater. Sci. 11, 159 (2006)

[2] http://www.specialmetals.com/documents/ Inconel\%20alloy\%20718.pdf

[3] Y. Huang, T.G. Langdon, J. Mater. Sci. 42, 421 (2007)

[4] Sh.Kh. Mukhtarov, V.A. Valitov, N.R. Dudova, Rev. Adv. Mater. Sci. 25, 219 (2010)

[5] Sh. Mukhtarov, V. Valitov and N. Dudova, Superalloys 718, 625, 706, and Various Derivatives, 507 (2005)

[6] Sh. Mukhtarov, Mater. Sci. Forum, 633-634, 569 (2010)

[7] S.K. Mukhtarov, A.G. Ermachenko, Rev. Adv. Mater. Sci. 31, 151 (2012)

[8] Y.S. Song, M.R. Lee, J.T. Kim, Superalloys 718, 625, 706 and Derivatives, 539 (2005)

[9] M. Clavel, A. Pineau, Mater. Sci. Eng., 55, 157 (1982)

[10] M. Dao, L. Lu, R.J. Asaro, J.T.M. De Hosson, E. Ma, Acta Mater. 55, 4041 (2007) 